\title{
A Novel Dual-Shorting Point PIFA (GSM850 to IMT-A) for Mobile Handsets
}

\author{
Pengcheng Li, Jin Pan, Deqiang Yang, and Pingzai Nie \\ Department of Microwave Engineering, School of Electronic Engineering, University of Electronic Science and Technology of \\ China (UESTC), Chengdu 610054, China
}

Correspondence should be addressed to Pengcheng Li; lipengcheng1986@yeah.net

Received 28 June 2013; Accepted 1 August 2013

Academic Editor: Xiao Ping Chen

Copyright (C) 2013 Pengcheng Li et al. This is an open access article distributed under the Creative Commons Attribution License, which permits unrestricted use, distribution, and reproduction in any medium, provided the original work is properly cited.

\begin{abstract}
A novel planar inverted-F antenna (PIFA) with dual-shorting points is proposed for multiband mobile handsets. The antenna comprises a meandered strip, a feeding point, two shorting points, and a slotted ground plane. For bandwidth enhancement of DCS/PCS/UMTS/WLAN 11.b/LTE2300/2500 and IMT-Advanced (International Mobile Telecommunications-Advanced), the antenna applies a dual-shorting points design, which generates a multimode between 1707 and $2815 \mathrm{MHz}$. The proposed antenna has good impedance matching characteristics for GSM (824-960 MHz)/DCS (1710-1880 MHz)/PCS (1850-1990 MHz)/UMTS (1920$2170 \mathrm{MHz}) / \mathrm{LTE}(2300-2400 \mathrm{MHz}, 2500-2690 \mathrm{MHz}) / \mathrm{WLAN} 11 . \mathrm{b}(2400-2480 \mathrm{MHz})$ and IMT-A (4200-4800 MHz). The measured radiation efficiencies of the proposed antenna were all higher than 60\% in GSM850/900, DCS/PCS, UMTS, LTE2300/2500, and WLAN $802.11 \mathrm{~b}$, and it is up to $86 \%$ in IMT-A.
\end{abstract}

\section{Introduction}

With the rapid development of wireless communications, the multistandard mobile communication systems (MSMCS) are required with low cost and compact size. Recently, the longterm evolution (LTE) system is introduced to afford better mobile services to the wireless wide area network (WWAN) and $4 \mathrm{G}$ (IMT-Advanced) [1-3]. Owing to the overall size limited for the placing of mobile terminal antenna, it becomes more difficult to achieve wide bandwidths. Conventional planar inverted-F antennas (PIFAs) are no longer a suitable option because of narrow bandwidth.

In order to obtain a wide frequency band, the coupled-fed structure is usually applied [4-7]. However, the performance, especially the high-frequency band, is susceptible to the width of the coupling gap. It is difficult to manufacture, and the cost will be increased significantly. Also, it is not suitable for IMT-A (4200-4800 MHz) operation. In order to obtain a compact-size antenna with large and multiple-frequency band, many other constructions for PIFA are applied with probe feeding $[1-3,8]$. However, in these designs, it is difficult to realize multiband and wideband operations at the same time. Besides, with microelectromechanical systems (MEMS) element $[4-7,9]$, the cost is increased inevitably.
In this paper, a compact and low-profile antenna is presented. The proposed design has a wide bandwidth, a reduced size, and a high efficiency [10-13]. The presented PIFA occupies a small volume of $46 \times 19 \times 5.5 \mathrm{~mm}^{3}$. In particular, lowfrequency band operation is achieved by two parallel openend slots on the ground plane. Based on the joint disposition of the PIFA and a meandered monopole in the structure, the multiband operation is realized. Reflection coefficient less than $-6 \mathrm{~dB}$ is obtained in $704-970 \mathrm{MHz}$ (31.8\% relative bandwidth, GSM850/900), $1575-2820 \mathrm{MHz}$ (56.7\% relative bandwidth, DCS/PCS/UMTS/LTE2300/25000), and 3850$5490 \mathrm{MHz}$ (35.1\% relative bandwidth, IMT-A), respectively.

Another issue of mobile terminal antenna is the radiation efficiency. In our design, the efficiency is up to $69 \%$ at low-frequency band, it and is more than $52 \%$ in the highfrequency band. The structure of the rest of the paper is given as follows. In Section 2, geometric structure and prototype of the PIFA is first presented. With dual-shorting point structure, the effect of antenna geometric parameters on performance is discussed in details. To validate our design, simulation and measurement results are demonstrated in Section 3 for comparison. Finally, conclusions are summarized in Section 4. 


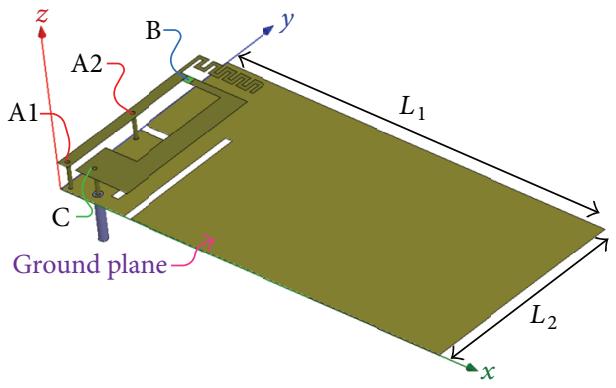

(a)

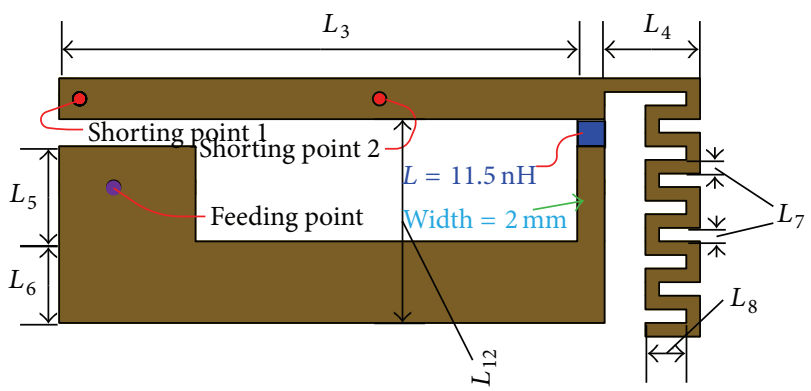

(b)

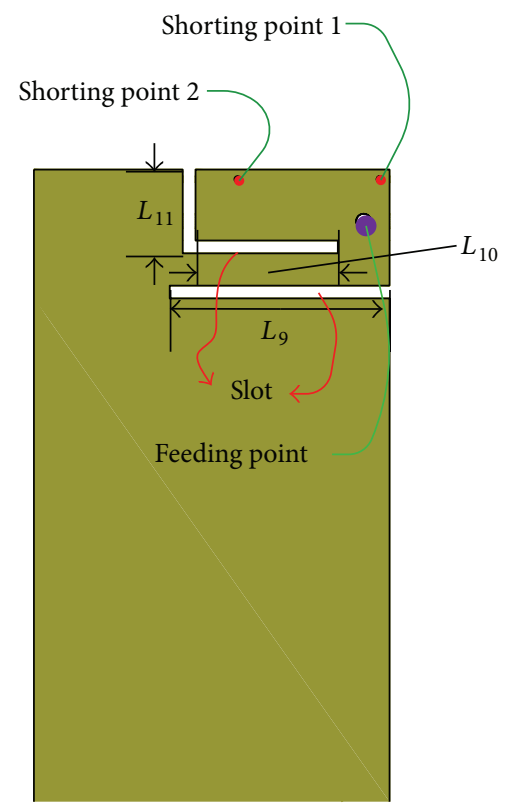

(c)

Figure 1: Proposed antenna configuration: (a) geometry of the proposed antenna, (b) detailed dimensions of the patch (top view), and (c) detailed dimensions of the ground plane (back view).

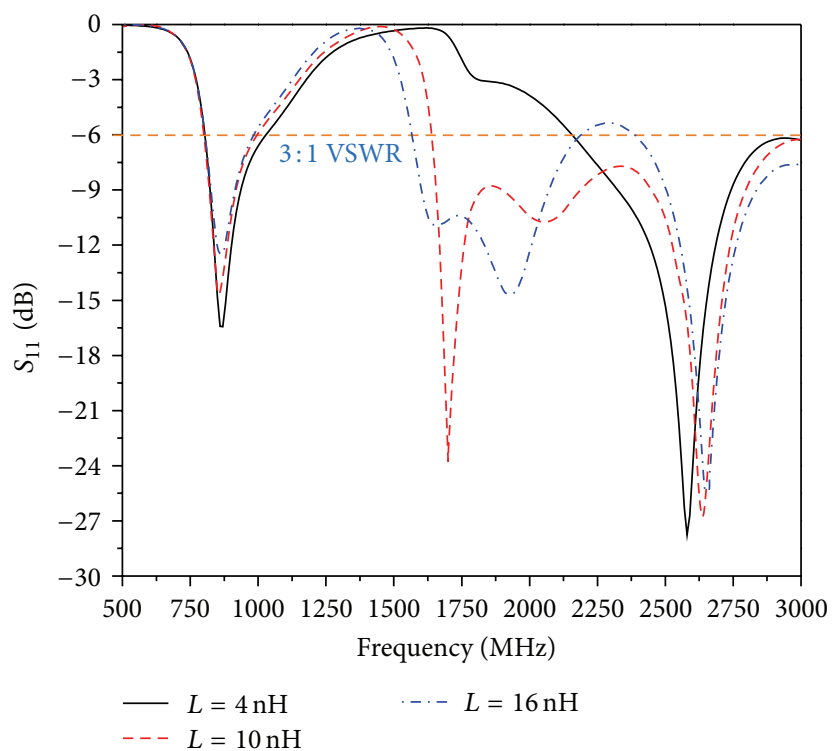

FIGURE 2: Simulated $S$ parameter as a function of $L$. 


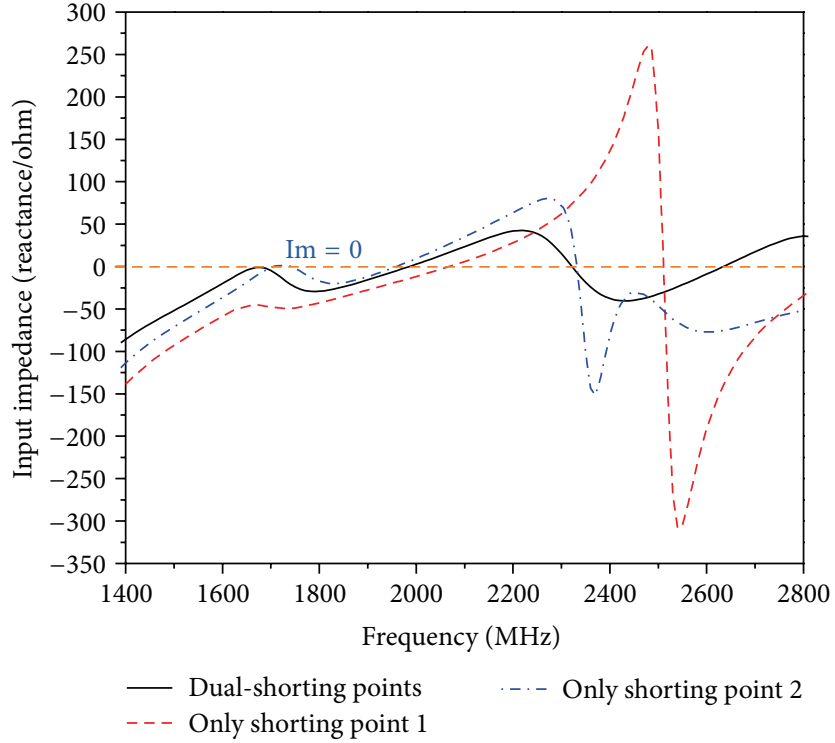

(a)

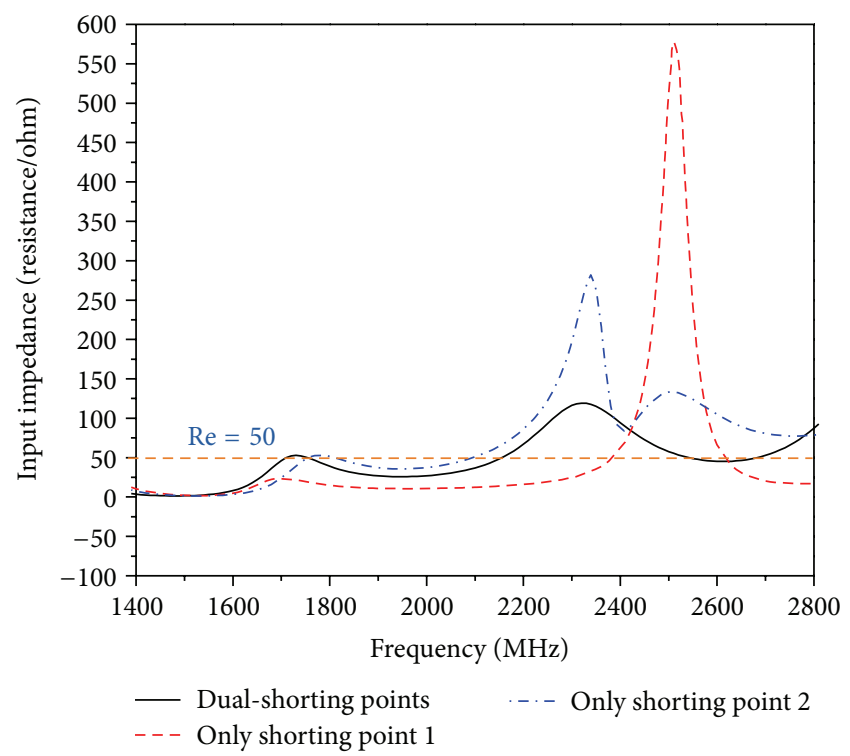

(b)

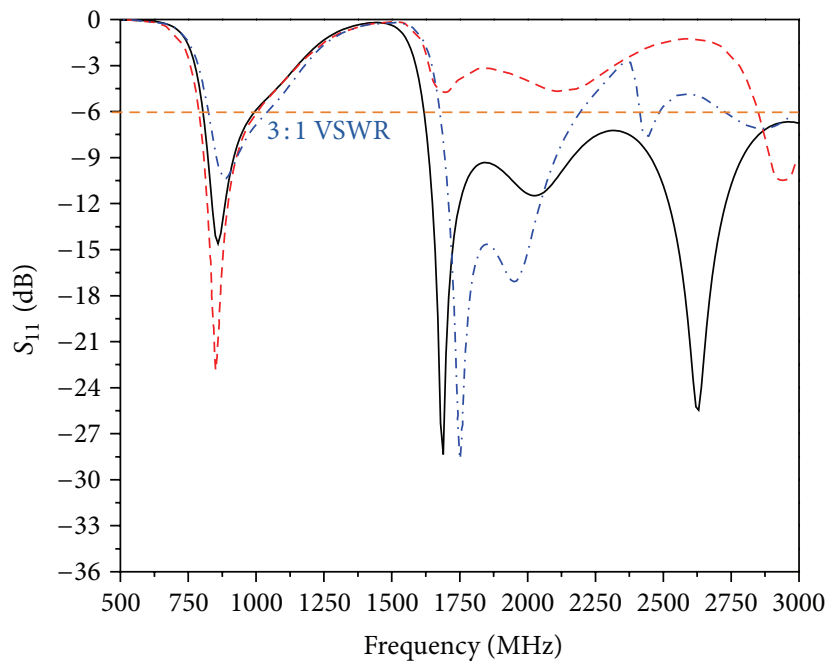

(c)

FIGURE 3: Simulated results with shorting points 1 and 2: (a) input impedance (reactance), (b) input impedance (resistance), and (c) $S$ parameter.

\section{Antenna Design and Parametric Study}

The proposed antenna structure is shown in Figure 1. Length of handset boxes model used in the simulation and measurement is as those used today.

Its dimensions are given as follows: $L_{1}=110 \mathrm{~mm}, L_{2}=$ $55 \mathrm{~mm}, L_{3}=38 \mathrm{~mm}, L_{4}=6 \mathrm{~mm}, L_{5}=8 \mathrm{~mm}, L_{6}=6 \mathrm{~mm}$, $L_{7}=1 \mathrm{~mm}, L_{8}=3 \mathrm{~mm}, L_{9}=32 \mathrm{~mm}, L_{10}=24 \mathrm{~mm}, L_{11}=$ $10 \mathrm{~mm}, L_{12}=10 \mathrm{~mm}$, and $L_{13}=40 \mathrm{~mm}$. The little inductor is only $2 \times 2 \mathrm{~mm}^{2}$. But the presented PIFA totally occupies $46 \times$ $19 \mathrm{~mm}^{2}$.

Figure 1(a) shows the 3D mode of the proposed antenna. Points A (A1 and A2) and point $\mathrm{C}$ are the shorting points and the feeding point, respectively. For practical mobile handset application, the PIFA is fed using a $50 \mathrm{ohm} \mathrm{mini-}$ coaxial line at point $\mathrm{C}$. At point $\mathrm{B}$, there is a chip-inductorloaded strip which contributes to a wideband covering the DCS/PCS/UMTS/LTE2300/2500 and WLAN 11.b operation [9-12, 14-16]. The chip inductor used in the PIFA has an inductance of $11.5 \mathrm{nH}$. With the shorting points A1 and A2 in Figures 1(a) and 1(b), the meandered strip is proposed as a PIFA with two shorting points. In Figure 1(c), the two slots of the ground plane are applied for the low-frequency resonant band and for enhancing the antenna return loss in the lower part of the band [7, 9, 14-16].

Based on the bandwidth specification of $3: 1$ VSWR $(6 \mathrm{~dB}$ return loss), which is widely approved as the fundamental design requirement of the internal handset antenna, the 


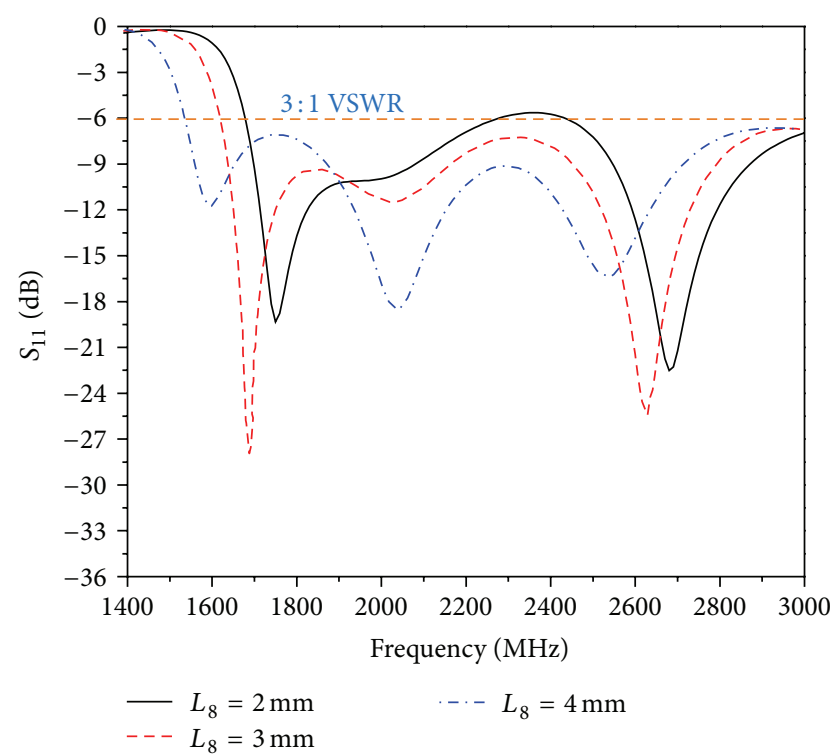

(a)

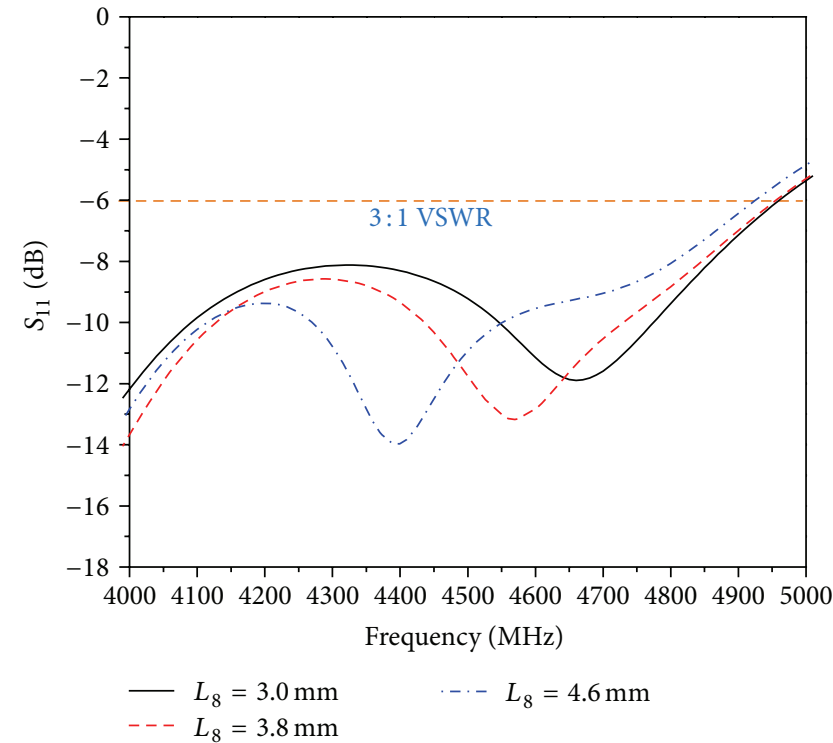

(b)

FIGURE 4: $S$ parameter as a function of (a) $L_{8}(1400-3000 \mathrm{MHz})$ and (b) $L_{8}(4000-5000 \mathrm{MHz})$.

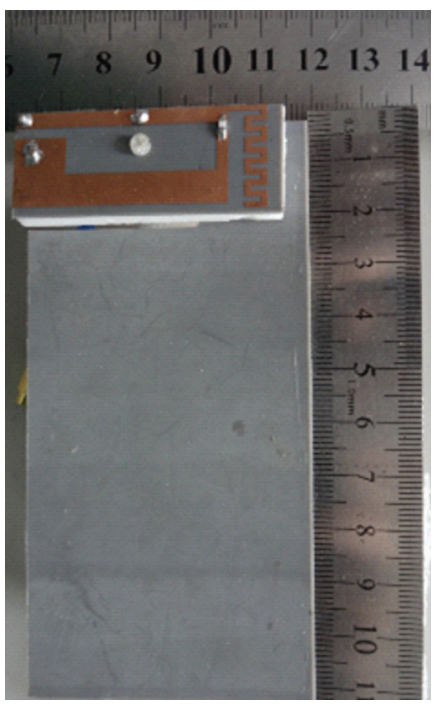

(a)

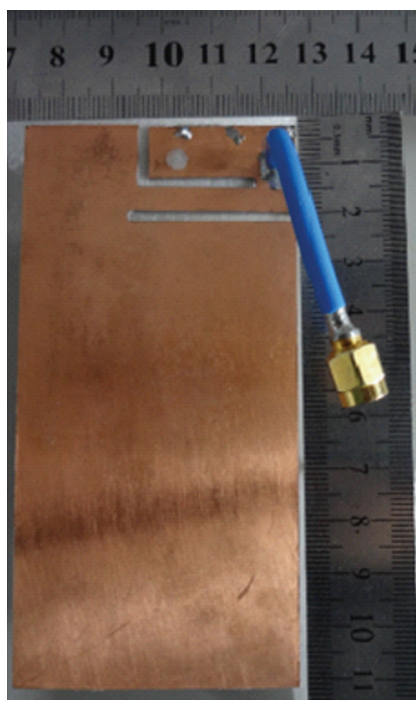

(b)

Figure 5: Photos of the manufactured antenna: (a) top side and (b) back side.

simulated $S$ parameter of the proposed PIFA covers 745$1175 \mathrm{MHz}, 1707-2815 \mathrm{MHz}$, and $3600-4900 \mathrm{MHz}$ [11-13, 1721]. The chip inductor with an inductance of $11.5 \mathrm{nH}(L)$ is applied to the proposed PIFA. This chip inductor is used to improve the bandwidth required for DCS/PCS.

Figure 2 shows the influence of the chip inductor $L$ for $S$ parameter. Stronger influence on the impedance matching of DCS/PCS/UMTS can be observed, while the inductor $L$ is changed from 4 to $16 \mathrm{nH}$. When a smaller inductance is used, the obtained bandwidth is decreased due to the decreasing of its resonant mode. After the optimizing, the impedance matching is improved when $L$ is $11.5 \mathrm{nH}$. A comparison of the simulation reflection coefficient and the input impedance (including the real and imaginary parts) is presented in Figure 3. Quite different from the obtained two resonant modes at about 1800 and $2600 \mathrm{MHz}$ of the proposed PIFA, there is only one resonant mode excited at about 1900 for the single-shorted point antenna. The structure is helpful in achieving better impedance matching for UMTS/WLAN 11.b/LTE2300/2500 operation. In addition, as seen in Figure 3(c), the excited resonant mode for the higher-frequency band $(2300-3000 \mathrm{MHz})$ is contributed by dual-shorting points.

The resonant mode at $1700 \mathrm{MHz}$ and $2600 \mathrm{MHz}$ also shifts down with the increasing of the length of the meandered strip (the function $L_{8}$ ). In Figure $4(\mathrm{a})$, the simulated $S_{11}$ 


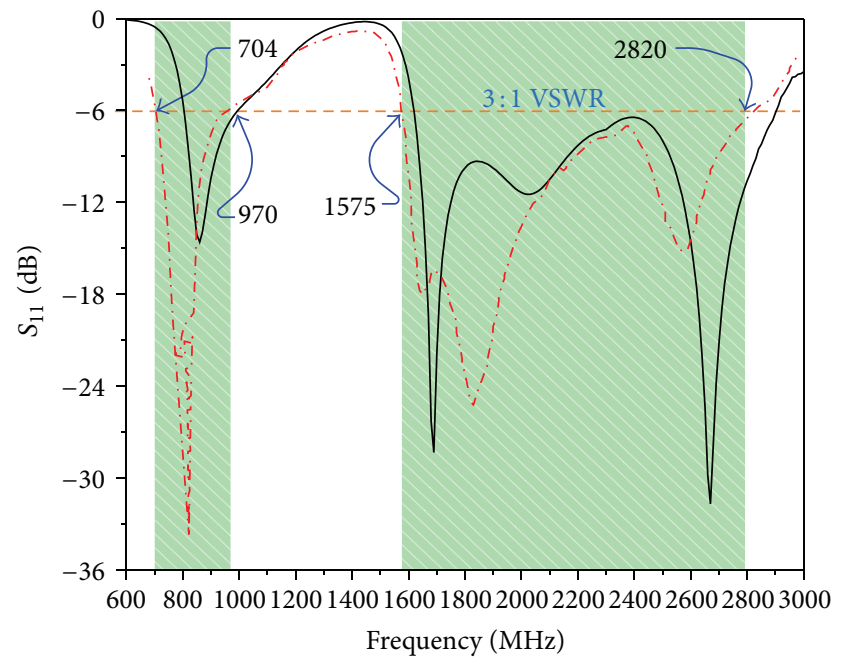

- Simulated

...- Measured

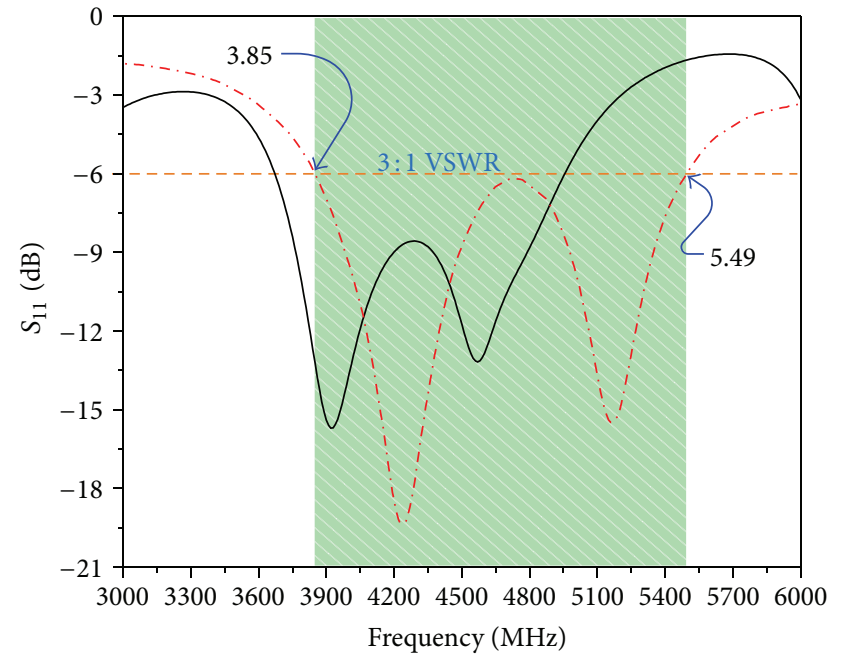

- Simulated

...- Measured

(a)

(b)

FIGURE 6: Measured $S$ parameter and simulated $S$ parameter: (a) 600-3000 MHz and (b) 3000-6000 MHz.

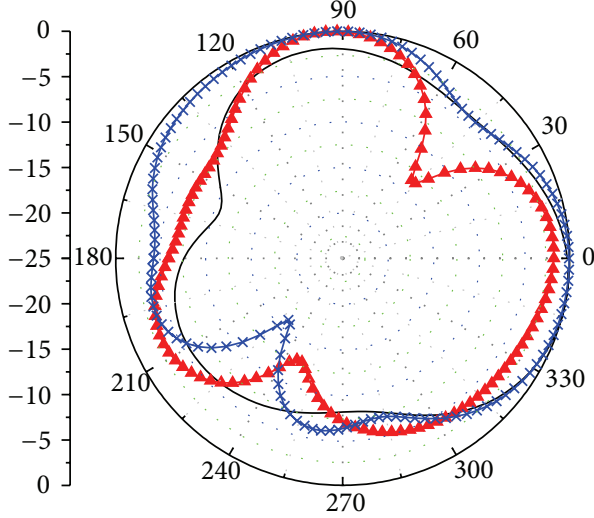

(a)

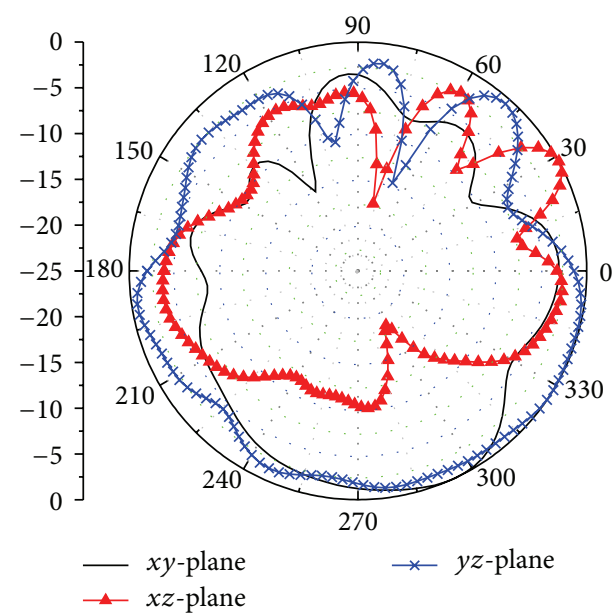

(c)

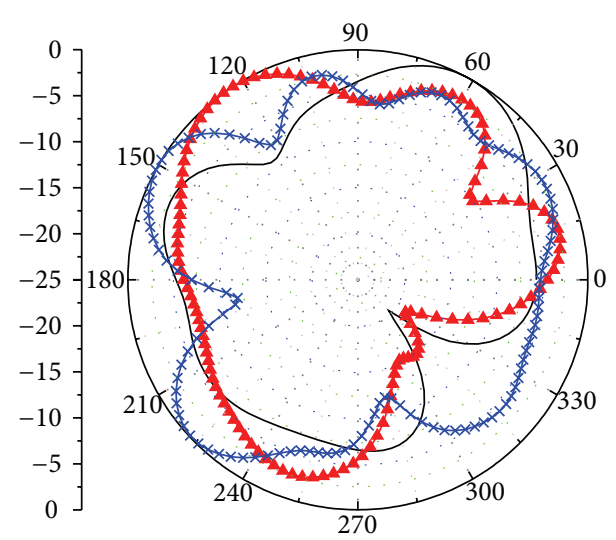

(b)

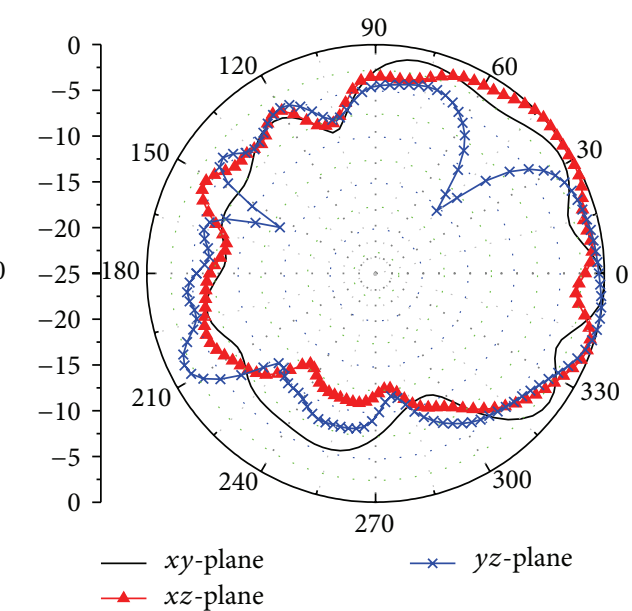

(d)

FIgURE 7: Measured 2D radiation patterns: (a) $900 \mathrm{MHz}$, (b) $1900 \mathrm{MHz}$, (c) $2500 \mathrm{MHz}$, and (d) $4500 \mathrm{MHz}$. 


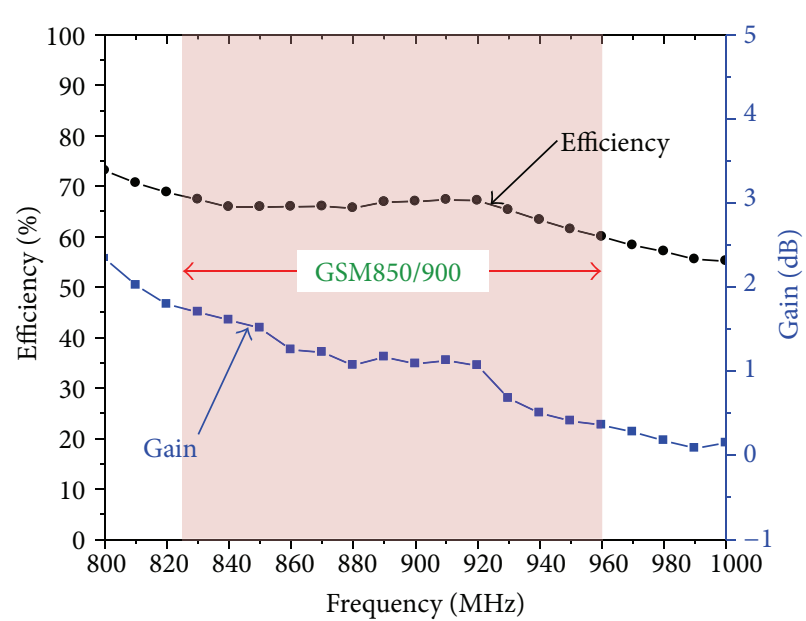

(a)

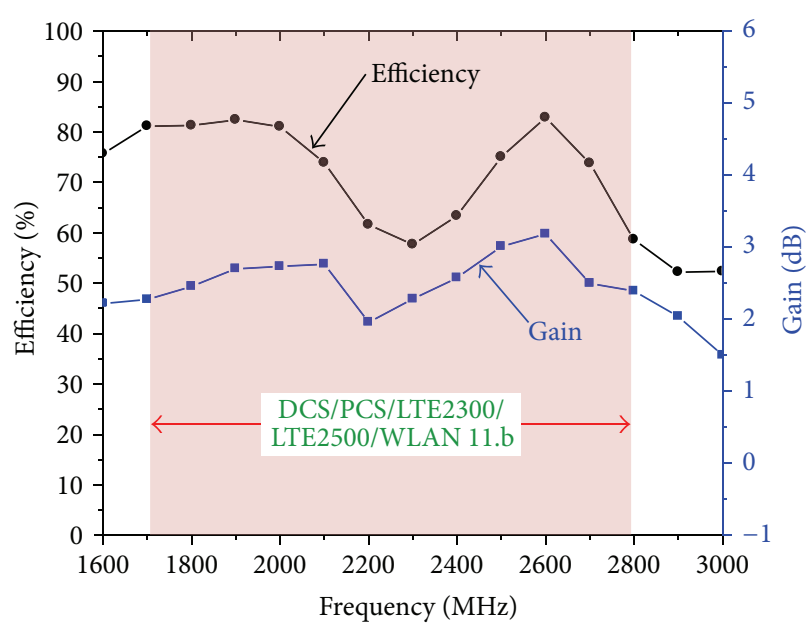

(b)

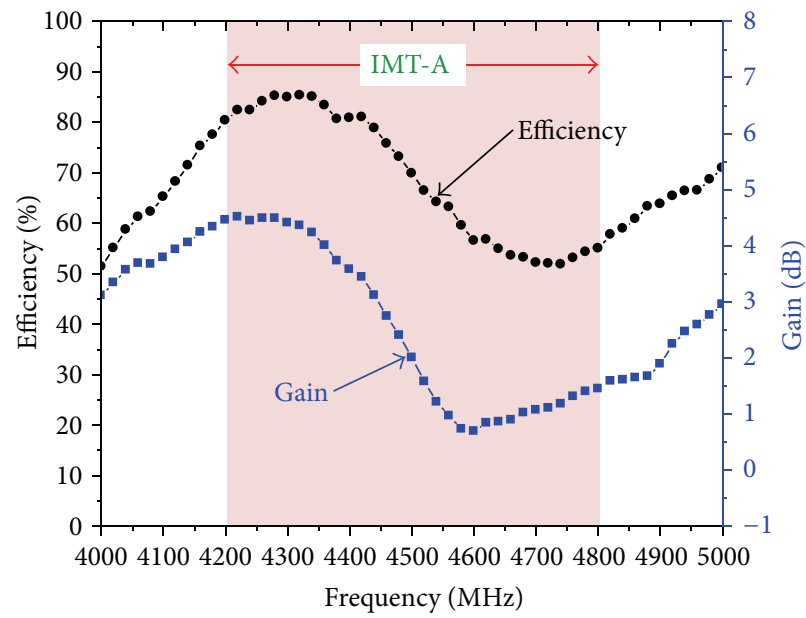

(c)

FIGURE 8: Measured antenna peak gain and radiation efficiency: (a) GSM850/900, (b) DCS1800/PCS1900/UMTS/WLAN 11.b/LTE2300/2500, and (c) IMT-A.

$(1400-3000 \mathrm{MHz})$ is presented when the length $L_{8}$ varied from $2 \mathrm{~mm}$ to $4 \mathrm{~mm}$. Besides, other parameters of the antenna are the same as given in Figure 1. Strong effects on the excited resonant modes indicate that proper selection of the $L_{8}$ is important in the proposed PIFA. The impedance matching over the DCS/PCS band is also strengthened. The simulated results of three different lengths $L_{8}=3,3.8$, and $4.6 \mathrm{~mm}$ are presented in Figure 4(b). Similar results can be observed compared with the results shown in Figure 4(a). The length $L_{8}$ of the meandered strip has a significant effect on the band of 4200-4800 MHz (IMT-A).

\section{Measured Results}

Based on the parameters study in Section 2, the PIFA prototype is manufactured as shown in Figure 5. Figure 6 presents the measured $S$ parameter and the simulated $S$ parameter. Because the value of $L$ is not accurate to $11.5 \mathrm{nH}$, the measured data result is even better than that of the simulation. Three wide operating bands have been obtained for the antenna.
The radiation patterns, the total efficiency, and the peak gain are measured by the SATIMO measurement system. Figure 7 shows the normalized pattern in three principal planes. The measured total efficiency including the mismatching loss for the proposed antenna is presented in Figure 8. Over the lower band $(800-1000 \mathrm{MHz}$ and $1600-$ $3000 \mathrm{MHz}$, Figures 8(a) and 8(b)), the total efficiency and the peak gain of the operation frequency band are $52 \%-55 \%$ and $0.3-2.8 \mathrm{dBi}$, respectively. For the upper band shown in Figure $8(\mathrm{c})$, the antenna gain varies from 0.7 to $4.1 \mathrm{dBi}$, while the total efficiency is better than $52 \%$. From the obtained results, the proposed design for PIFA is a good option for practical internal mobile applications.

\section{Conclusions}

This paper presents a new design for PIFA. Using two open-end parallel slots in the ground plane, a significant improvement in the antenna operational bandwidth at the lower-frequency band can be achieved. The higher-frequency operating band is achieved by comprising two meandered 
monopoles. Thus, triple-band impedance $(704-970 \mathrm{MHz}$, $1575-2820 \mathrm{MHz}$, and $3850-5490 \mathrm{MHz}$ ) for $\mathrm{VSWR} \leqq 3$ is obtained. The main design dimensions of the meandered strip are studied and discussed. Measured results show that the proposed antenna has good radiation characteristics, including total efficiency and peak gain. With the presence of the multiband and the wideband features, the proposed design of PIFA is attractive for the practical mobile phones.

\section{References}

[1] R. Sánchez-Montero, S. Salcedo-Sanz, J. A. Portilla-Figueras et al., "Hybrid PIFA-patch antenna optimized by evolutionary programming," Progress in Electromagnetics Research, vol. 108, pp. 221-234, 2010.

[2] M. A. Ebrahimi-Ganjeh and A. R. Attari, "Interaction of dual band helical and PIFA handset antennas with human head and hand," Progress in Electromagnetics Research, vol. 77, pp. 225242, 2007.

[3] P. J. Soh, S. J. Boyes, G. A. E. Vandenbosch, Y. Huang, and S. L. Ooi, "On-body characterization of dual-band all-textile PIFAs," Progress in Electromagnetics Research, vol. 129, pp. 517-539, 2012.

[4] R. Caso, A. D’Alessandro, A. A. Serra, P. Nepa, and G. Manara, "A compact dual-band PIFA for DVB-T and WLAN applications," IEEE Transactions on Antennas and Propagation, vol. 60, no. 4, pp. 2084-2087, 2012.

[5] H. Wang and M. Zheng, "An internal triple-band WLAN antenna," IEEE Antennas and Wireless Propagation Letters, vol. 10, pp. 569-572, 2011.

[6] Y. Sung, "Compact Quad-band reconfigurable antenna for mobile phone application," Electronics Letters, vol. 48, no. 16, pp. 977-979, 2012.

[7] P. Jack Soh, G. A. E. Vandenbosch, S. Liam Ooi, and N. Husna Mohd Rais, "Design of a broadband all-textile slotted PIFA," IEEE Transactions on Antennas and Propagation, vol. 60, no. 1, pp. 379-384, 2012.

[8] Y. Zhu, F. Gao, X. Yang et al., "The effect of microwave emission from mobile phones on neuron survival in rat central nervous system," Progress in Electromagnetics Research, vol. 82, pp. 287298, 2008.

[9] R. Hossa, A. Byndas, and M. E. Bialkowski, "Improvement of compact terminal antenna performance by incorporating open-end slots in ground plane," IEEE Microwave and Wireless Components Letters, vol. 14, no. 6, pp. 283-285, 2004.

[10] M. Y. Man, R. Yang, Z. Y. Lei, Y. J. Xie, and J. Fan, "Ultrawideband planer inverted-F antennas with cut-etched ground plane," Electronics Letters, vol. 48, no. 14, pp. 817-818, 2012.

[11] K.-J. Kim, S.-H. Lee, B.-N. Kim et al., "Small antenna with a coupling feed and parasitic elements for multiband mobile applications," IEEE Antennas and Wireless Propagation Letters, vol. 10, pp. 290-293, 2011.

[12] J. Kim, C. Yang, T. Yun, and C. Jung, "Multimode multiband (VHF/UHF/L/802.11a/b) antennas for broadcasting and telecommunication services," IEEE Antennas and Wireless Propagation Letters, vol. 10, pp. 41-44, 2011.

[13] C.-H. Chang and K.-L. Wong, "Printed $\lambda / 8$-PIFA for pentaband WWAN operation in the mobile phone," IEEE Transactions on Antennas and Propagation, vol. 57, no. 5, pp. 1373-1381, 2009.

[14] K.-L. Wong, W.-Y. Chen, and T.-W. Kang, "On-board printed coupled-fed loop antenna in close proximity to the surrounding ground plane for penta-band WWAN mobile phone," IEEE Transactions on Antennas and Propagation, vol. 59, no. 3, pp. 751-757, 2011.

[15] K.-L. Wong, W.-J. Chen, and T.-W. Kang, "Small-size loop antenna with a parasitic shorted strip monopole for internal WWAN notebook computer antenna," IEEE Transactions on Antennas and Propagation, vol. 59, no. 5, pp. 1733-1738, 2011.

[16] K.-L. Wong, Y.-W. Chang, and S.-C. Chen, "Bandwidth enhancement of small-size planar tablet computer antenna using a parallel-resonant spiral slit," IEEE Transactions on Antennas and Propagation, vol. 60, no. 4, pp. 1705-1711, 2012.

[17] A. P. Feresidis and Q. Li, "Miniaturised slits for decoupling PIFA array elements on handheld devices," Electronics Letters, vol. 48, no. 6, pp. 310-312, 2012.

[18] Y. K. Park and Y. Sung, "A reconfigurable antenna for Quadband mobile handset applications," IEEE Transactions on Antennas and Propagation, vol. 60, no. 6, pp. 3003-3006, 2012.

[19] Z.-N. Ying, "Antennas in cellular phones for mobile communications," Proceedings of the IEEE, vol. 100, no. 7, pp. 2286-2296, 2012.

[20] S. M. Mazinani and H. R. Hassani, "A wideband internal plate loaded planar monopole antenna for mobile handset," Journal of Electromagnetic Waves and Applications, vol. 23, no. 10, pp. 1273-1282, 2009.

[21] B. H. Sun, J. F. Li, and Q. Z. Liu, "Compact broadband printed antenna for multi-functional mobile terminals," Journal of Electromagnetic Waves and Applications, vol. 22, no. 8-9, pp. 1292-1298, 2008. 

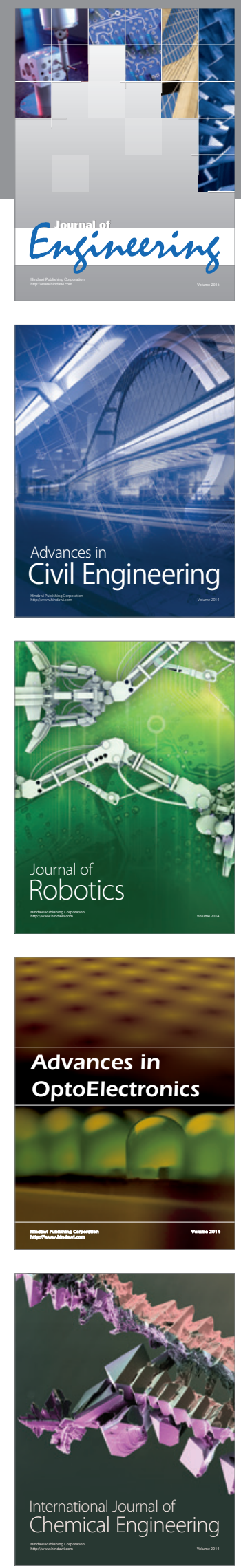

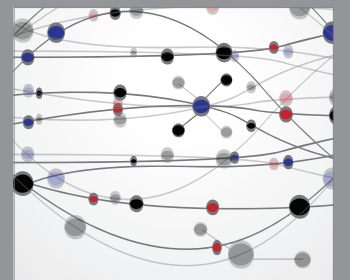

The Scientific World Journal
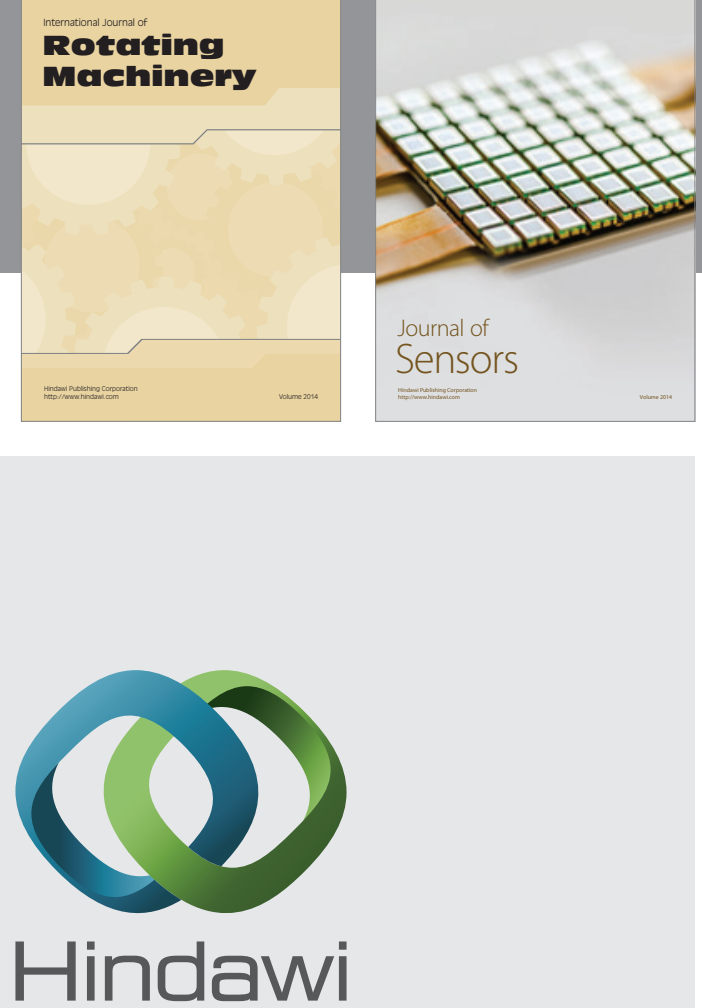

Submit your manuscripts at http://www.hindawi.com
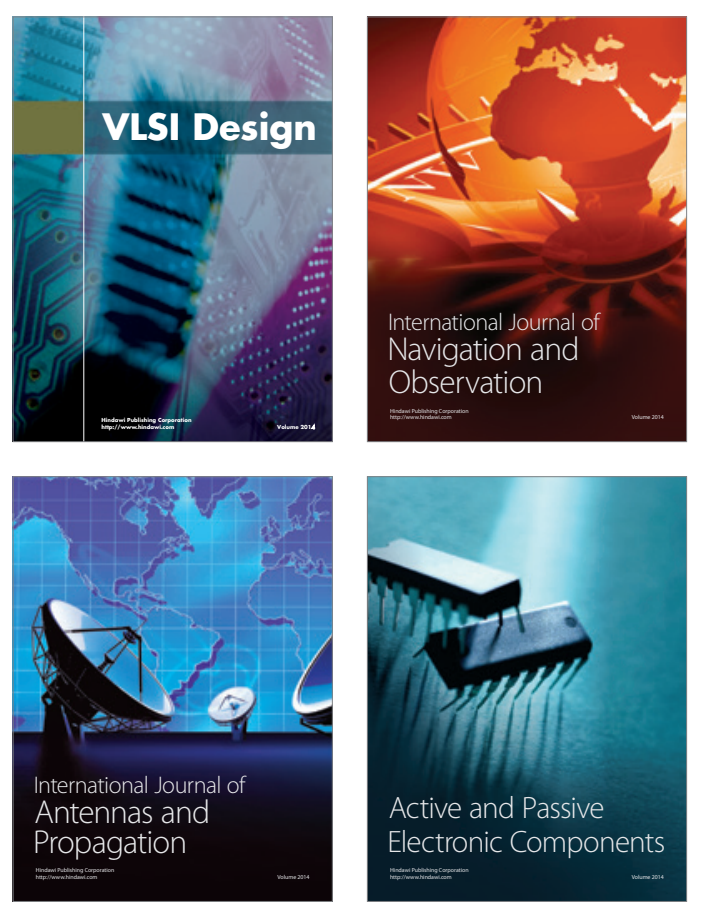
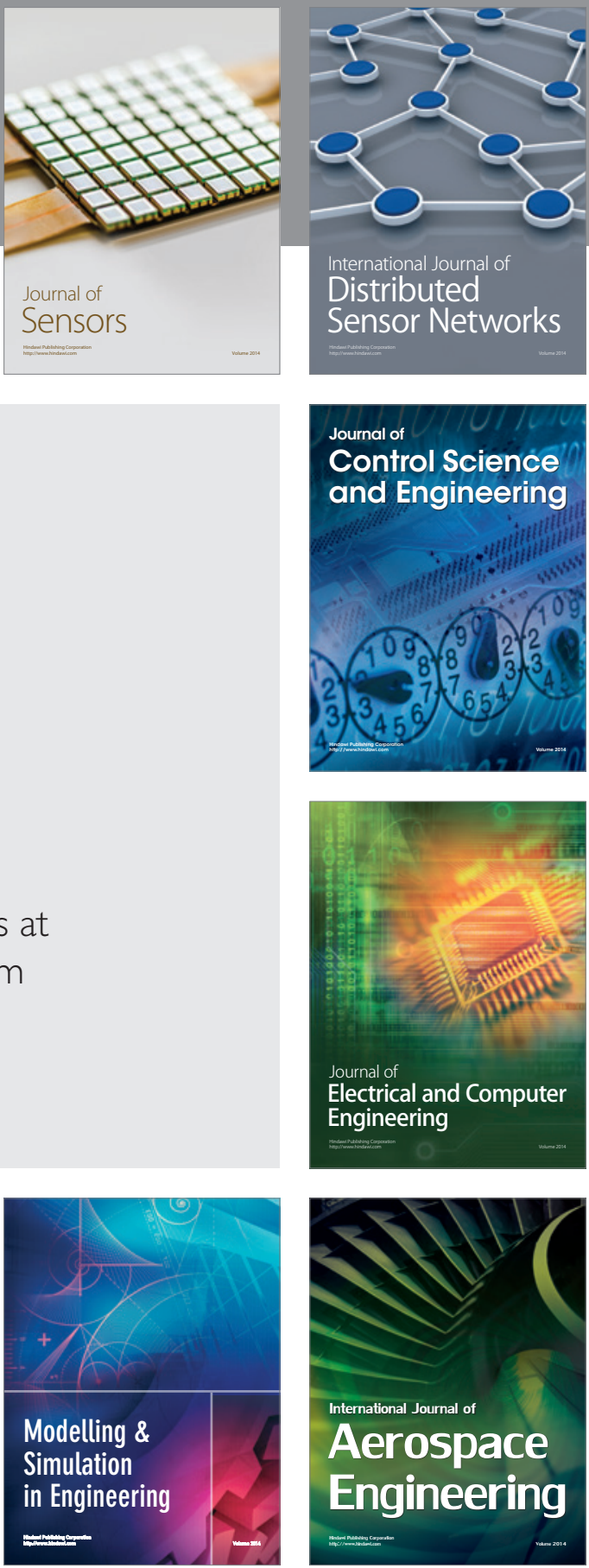

Journal of

Control Science

and Engineering
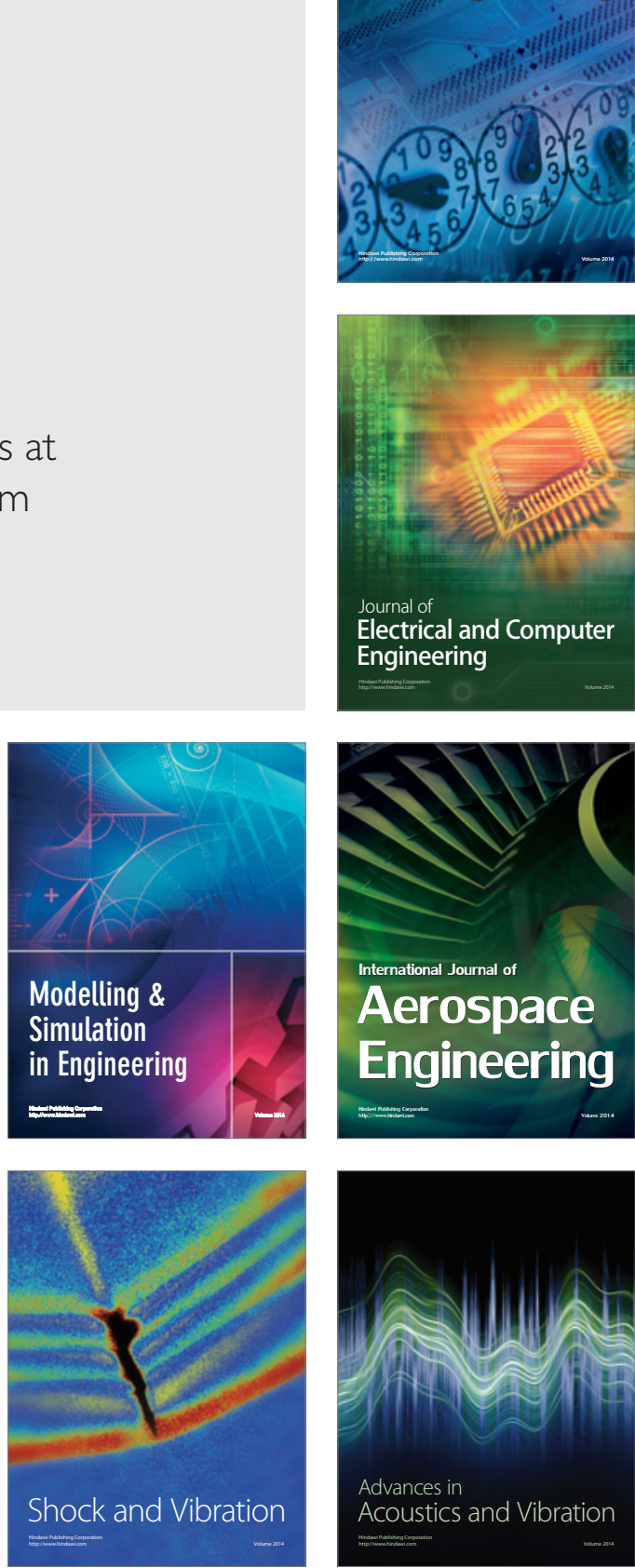